\title{
Risk of Stroke and Bleeding in Atrial Fibrillation Treated with Apixaban Compared with Warfarin
}

\author{
Marie Bradley, PhD, MPharm, MSc. $P H^{7}$, Emily C. Welch, $M P H^{2}$, \\ Efe Eworuke, PhD, MSc., B.Pharm', David J. Graham, MD, MPH' , Rongmei Zhang, PhD ${ }^{3}$, \\ and Ting-Ying Huang, $P h D^{2}$
}

\begin{abstract}
'Office of Surveillance and Epidemiology, Center for Drug Evaluation and Research, Food and Drug Administration, Silver Spring, MD, USA; ${ }^{2}$ Department of Population Medicine, Harvard Medical School and Harvard Pilgrim Health Care Institute, Boston, MA, USA; ${ }^{3}$ Office of Biostatistics, Center for Drug Evaluation and Research, Food and Drug Administration, Silver Spring, MD, USA.
\end{abstract}

\begin{abstract}
BACKGROUND: A previous FDA study reported a favorable benefit risk for apixaban compared with warfarin for stroke prevention in older non-valvular atrial fibrillation (NVAF) patients ( $\geq 65$ years). However, it remains unclear whether this favorable benefit risk persists in other populations including younger users. We examined if a similar benefit risk was observed in the Sentinel System and if it varied by age group.
\end{abstract}

OBJECTIVE: To examine the risk of ischemic stroke, gastrointestinal (GI) bleeding, and intracranial hemorrhage (ICH) in apixaban users compared with warfarin users in Sentinel Distributed Database (SDD).

DESIGN AND PARTICIPANTS: A retrospective new user cohort study was conducted among patients, 21 years and older initiating apixaban and warfarin for NVAF, between December 28, 2012, and June 30, 2018, in the SDD.

MAIN MEASURES: Cox proportional hazard regression was used to estimate the hazard ratios (HR) and 95\% confidence intervals (95\% CI) for each outcome (ischemic stroke, GI bleeding, and ICH) in propensity score matched apixaban users compared with the warfarin users. Subgroup analyses by age (21-64, 65-74, and 75+ years) were conducted.

KEY RESULTS: After matching, 55.3\% and 58.4\% ( $n=$ 55,038 ) of the apixaban and warfarin users were included in the main analysis. GI bleeding was the most common outcome. The HR (95\% CI) for GI bleeding, ICH, and ischemic stroke in apixaban users compared with warfarin users were $0.57(0.50-0.66), 0.53(0.40-0.70)$, and 0.56 (0.45-0.71) respectively. The reduced risk of these outcomes in apixaban compared with warfarin users persisted across age groups.

CONCLUSION: In NVAF patients of all ages initiating either apixaban or warfarin for stroke prevention in the Sentinel System, apixaban was associated with a decreased risk of GI bleeding, ICH, and ischemic stroke compared with warfarin. Among patients less than 65 years of age, apixaban use was associated with a decreased risk of GI bleeding and ischemic stroke.

Prior presentations: none

Electronic supplementary material The online version of this article (https://doi.org/10.1007/s11606-020-06180-8) contains supplementary material, which is available to authorized users.

Received March 5, 2020

Accepted August 24, 2020

Published online September 28, 2020
KEY WORDS: non-valvular atrial fibrillation; apixaban; warfarin; bleeding; stroke; Sentinel System.

J Gen Intern Med 35(12):3597-604 DOI: $10.1007 / \mathrm{s} 11606-020-06180-8$

(c) Society of General Internal Medicine (This is a U.S. government work and not under copyright protection in the U.S.; foreign copyright protection may apply) 2020

\section{INTRODUCTION}

Non-valvular atrial fibrillation (NVAF) is a common arrhythmia that independently increases the risk of ischemic stroke by fivefold. ${ }^{1,2}$ Estimates suggest that around 2.7-6.1 million Americans have NVAF and prevalence increases with age, particularly after 65 years. ${ }^{3,4}$ Prior to 2010, the mainstay of stroke prevention in NVAF was oral vitamin $\mathrm{K}$ antagonists, such as warfarin. ${ }^{5}$ Since then, four non-vitamin $\mathrm{K}$ antagonist oral anticoagulants (NOACs) have been approved in the USA for stroke prevention in patients with NVAF and serve as an alternative to the traditional warfarin option. NOACs do not require therapeutic monitoring and have simpler dosing regimens than warfarin. Dabigatran (approved in 2010) is a direct thrombin inhibitor, while rivaroxaban (2011), apixaban (2012), and edoxaban (2015) are factor Xa inhibitors and all of them have been shown to be non-inferior to warfarin for stroke prevention. ${ }^{6-8}$

NOAC use in the USA increased dramatically since 2010, especially in those aged under 65 years. ${ }^{9}$ A US study that examined NOAC use between 2010 and 2017 reported that from 2015, NOACs accounted for over $80 \%$ of new oral anticoagulant prescriptions among patients aged less than 65 years and that prescriptions for dabigatran, rivaroxaban, and apixaban exceeded warfarin. ${ }^{9}$ Across all age groups, apixaban was the most frequently prescribed oral anticoagulant since 2015 and accounted for half of new oral anticoagulant prescriptions in $2017 .{ }^{9}$ The increasing use of apixaban is likely related to increased evidence and recognition of its favorable benefit risk profile as recently reported in a large study among Medicare beneficiaries. ${ }^{10}$ That Medicare study, conducted among new users of NOACs and warfarin between 2010 and 2015, reported a lower risk of stroke, intracranial hemorrhage $(\mathrm{ICH})$, major extracranial bleeding, and death 
among apixaban users compared with warfarin users who were aged 65 years or older. ${ }^{10}$ These findings are in line with those from the pre-approval Apixaban for Reduction in Stroke and Other Thromboembolic Events in Atrial Fibrillation (ARISTOTLE) trial which showed that patients who received apixaban were less likely to die within 30 days of a major hemorrhagic event, were less likely to have non-major bleeding, and had lower rates of ICH compared with those who received warfarin. ${ }^{8}$ However, it remains unclear whether the lower risk of bleeding associated with apixaban use, seen among older patients in the ARISTOTLE trial and the Medicare study, would also be seen in younger users. Therefore, we sought to examine if a similar benefit risk profile for apixaban compared with warfarin was observed in the FDA Sentinel System and if this varied by age group. Specifically, we compared risk of stroke and bleeding in NVAF patients who initiated apixaban or warfarin.

\section{METHODS}

\section{Study Design}

A retrospective cohort study was conducted.

\section{Cohort}

New initiators of apixaban or warfarin, aged 21 years or more with a diagnosis of atrial fibrillation (AF) in the previous 183 days, between December 28, 2012, and June 30, 2018, were identified in the Sentinel Distributed Database (SDD). Sentinel comprises electronic health care data from a distributed network of US-based data partners. These data partners, mostly commercial health insurers and integrated delivery care networks, convert their data into the Sentinel Common Data Model. The data domains include patient demographics; health insurance enrollment; diagnoses and procedures during inpatient, outpatient, and emergency room encounters; and outpatient pharmacy dispensing records. ${ }^{11-13}$ This study included data outside of the Medicare fee-for-service population in order to better differentiate our population from that in the prior Medicare study. ${ }^{10}$ Cohort members maintained continuous enrollment for at least 183 days before apixaban or warfarin initiation during which gaps in medical and prescription drug coverage of up to 45 days were allowed. Patients were excluded if they had evidence of the following conditions in the 183 days prior to and including date of drug initiation: any of the study outcomes (gastrointestinal (GI) bleeding, ICH, or ischemic stroke) as principal discharge diagnosis of an inpatient admission, an alternate indication for apixaban or warfarin use (deep vein thrombosis, pulmonary embolism, joint replacement, mitral stenosis, valve replacement, or valve repair), from any care setting. Those receiving dialysis in outpatient settings or who had a kidney replacement were excluded as there has been some controversy about the use of NOACs in dialysis patients and this might affect the use in those with kidney transplants also (see flow diagram in the Appendix: Fig. 1). We identified the exclusion conditions, exposure, outcomes, and covariates via outpatient pharmacy dispensing encoded in the National Drug Codes and medical encounter diagnoses and procedures encoded in the International Classification of Diseases, Ninth or Tenth Revision, Clinical Modification (ICD-9-CM or ICD-10-CM); the International Classification of Diseases, Tenth Revision, Procedure Coding System (ICD-10-PCS); Healthcare Common Procedure Coding System (HCPCS); and Current Procedural Terminology (CPT) codes. We performed all analyses using the Sentinel's Cohort Identification and Descriptive Analysis (CIDA) and Propensity Score Analysis tools, Version 5.4.4, with additional programming to calculate the risk scores.

\section{Exposure}

New users of apixaban (standard $5 \mathrm{mg}$ strength only) or warfarin (all strengths) whose first exposure occurred on or after December 28, 2012 (approval date for apixaban) were included. New use of apixaban or warfarin was defined as no use of any anticoagulant (apixaban, dabigatran, rivaroxaban, edoxaban, or warfarin) in the previous 183 days. The index date was defined as the dispensing date for the first eligible apixaban or warfarin dispensing during the study period. Each eligible member contributed only the earliest valid exposure episode in their entire health insurance enrollment history.

\section{Outcomes and Follow-Up}

The primary outcomes were an inpatient principal diagnosis for GI bleeding, ICH, or ischemic stroke. Outcomes were defined using previously validated algorithms based on ICD9-CM diagnosis codes in claim databases. These algorithms have reported positive predictive values ranging from 86 to 97\%. ${ }^{14-18}$ These ICD-9-CM-based algorithms were mapped to the ICD-10-CM coding system via forward-backward mapping $^{19,20}$ using the 2017 General Equivalence Mappings. ${ }^{21}$ Follow-up began on the day after the first dispensing of a study drug and continued until the first occurrence of any of the following: (1) outcome occurrence, (2) switching to a different anticoagulant, (3) disenrollment, (4) recorded death, (5) end of exposure episode, and (6) end of query period (June 30, 2018) or end of available data for data partners. Exposure episodes were considered continuous if gaps in days supplied were 3 days or less. Three days were chosen as an appropriate gap allowance based on the half-life of NOACs and the requirement that patients remain anticoagulated during follow-up. An episode extension of 3 days was added to the end of each exposure episode. A 14-day gap allowance and extension were applied in sensitivity analyses.

\section{Statistical Analysis}

Confounding Adjustment. Logistic regression was used to estimate the propensity score (PS) of initiating apixaban 
Table 1 Characteristics of New Initiators of Apixaban and Warfarin After Propensity Score Matching from December 28, 2012, to June 30, 2018

\begin{tabular}{|c|c|c|c|c|c|c|}
\hline \multirow[t]{2}{*}{ Characteristic* } & \multicolumn{2}{|c|}{ Apixaban } & \multicolumn{2}{|c|}{ Warfarin } & \multirow{2}{*}{$\begin{array}{l}\text { Absolute } \\
\text { difference }\end{array}$} & \multirow{2}{*}{$\begin{array}{l}\text { Stanardized mean } \\
\text { difference }\end{array}$} \\
\hline & $\begin{array}{l}N / \\
\text { mean }\end{array}$ & $\begin{array}{l}\text { \%/Std } \\
\text { Dev }^{\dagger}\end{array}$ & $\begin{array}{l}N / \\
\text { mean }\end{array}$ & $\begin{array}{l}\% / \text { Std } \\
\text { Dev }^{\dagger}\end{array}$ & & \\
\hline Patients $(N)$ & 55,038 & $55.3 \%$ & 55,038 & $58.4 \%$ & - & - \\
\hline \multicolumn{7}{|l|}{ Demographics } \\
\hline Mean age & 71.3 & 9.7 & 71.3 & 10.6 & -0.056 & -0.006 \\
\hline Age: $21-64$ years & 14,473 & $26.3 \%$ & 15,203 & $27.6 \%$ & -1.326 & -0.030 \\
\hline Age: $65-74$ years & 19,315 & $35.1 \%$ & 17,894 & $32.5 \%$ & 2.582 & 0.055 \\
\hline Age: $75+$ years & 21,250 & $38.6 \%$ & 21,941 & $39.9 \%$ & -1.255 & -0.026 \\
\hline Gender (male) & 33,394 & $60.7 \%$ & 33,476 & $60.8 \%$ & -0.149 & -0.003 \\
\hline Race (White) & 25,454 & $46.2 \%$ & 26,059 & $47.3 \%$ & -1.099 & -0.022 \\
\hline Race (Black or African American) & 2231 & $4.1 \%$ & 2288 & $4.2 \%$ & -0.104 & -0.005 \\
\hline Race (Unknown) & 26,810 & $48.7 \%$ & 26,186 & $47.6 \%$ & 1.134 & 0.023 \\
\hline Race (American Indian or Alaska Native) & 56 & $0.1 \%$ & 69 & $0.1 \%$ & -0.024 & -0.007 \\
\hline Race (Asian) & 240 & $0.4 \%$ & 222 & $0.4 \%$ & 0.033 & 0.005 \\
\hline Race (Native Hawaiian or other Pacific Islander) & 247 & $0.4 \%$ & 214 & $0.4 \%$ & 0.060 & 0.009 \\
\hline Year (2012) & - & $0.0 \%$ & 98 & $0.2 \%$ & -0.178 & - \\
\hline Year (2013) & 3021 & $5.5 \%$ & 10,985 & $20.0 \%$ & -14.47 & -0.445 \\
\hline Year (2014) & 9648 & $17.5 \%$ & 8337 & $15.1 \%$ & 2.382 & 0.064 \\
\hline Year (2015) & 14,566 & $26.5 \%$ & 9339 & $17.0 \%$ & 9.497 & 0.232 \\
\hline Year (2016) & 10,764 & $19.6 \%$ & 13,175 & $23.9 \%$ & -4.381 & -0.106 \\
\hline Year (2017) & 12,299 & $22.3 \%$ & 10,193 & $18.5 \%$ & 3.826 & 0.095 \\
\hline Year (2018) & 4740 & $8.6 \%$ & 2911 & $5.3 \%$ & 3.734 & 0.139 \\
\hline \multicolumn{7}{|l|}{ Recorded history of: } \\
\hline Prior combined comorbidity score & 2.9 & 2.5 & 3.0 & 2.6 & -0.109 & -0.043 \\
\hline \multicolumn{7}{|l|}{$\mathrm{CHA}_{2} \mathrm{DS}_{2} \mathrm{VaSc}$} \\
\hline Mean, Std & 3.2 & 1.5 & 3.2 & 1.5 & -0.016 & -0.010 \\
\hline $0-1$ & 8559 & $15.6 \%$ & 8363 & $15.2 \%$ & 0.356 & 0.010 \\
\hline 2 & 10,146 & $18.4 \%$ & 10,110 & $18.4 \%$ & 0.065 & 0.002 \\
\hline 3 & 13,272 & $24.1 \%$ & 13,294 & $24.2 \%$ & -0.040 & -0.001 \\
\hline 4 & 11,911 & $21.6 \%$ & 12,008 & $21.8 \%$ & -0.176 & -0.004 \\
\hline 5 & 7067 & $12.8 \%$ & 7142 & $13.0 \%$ & -0.136 & -0.004 \\
\hline$\geq 6$ & 4083 & $7.4 \%$ & 4121 & $7.5 \%$ & -0.069 & -0.003 \\
\hline \multicolumn{7}{|l|}{ HAS-BLED } \\
\hline Mean, Std & 2.2 & 1.0 & 2.2 & 1.1 & -0.014 & -0.013 \\
\hline $0-1$ & 14,764 & $26.8 \%$ & 14,455 & $26.3 \%$ & 0.561 & 0.013 \\
\hline 2 & 20,771 & $37.7 \%$ & 20,819 & $37.8 \%$ & -0.087 & -0.002 \\
\hline 3 & 13,308 & $24.2 \%$ & 13,345 & $24.2 \%$ & -0.067 & -0.002 \\
\hline$\geq 4$ & 6195 & $11.3 \%$ & 6419 & $11.7 \%$ & -0.407 & -0.013 \\
\hline Acute myocardial infarction-prior 1-30 days & 2609 & $4.7 \%$ & 2700 & $4.9 \%$ & -0.165 & -0.008 \\
\hline Acute myocardial infarction-prior $31-183$ days & 1457 & $2.6 \%$ & 1516 & $2.8 \%$ & -0.107 & -0.007 \\
\hline Cardiac ablation & 1115 & $2.0 \%$ & 1055 & $1.9 \%$ & 0.109 & 0.008 \\
\hline Cardioversion & 4310 & $7.8 \%$ & 4038 & $7.3 \%$ & 0.494 & 0.019 \\
\hline Coronary revascularization & 7656 & $13.9 \%$ & 7973 & $14.5 \%$ & -0.576 & -0.017 \\
\hline Diabetes & 19,141 & $34.8 \%$ & 19,284 & $35.0 \%$ & -0.260 & -0.005 \\
\hline Falls & 1770 & $3.2 \%$ & 1888 & $3.4 \%$ & -0.214 & -0.012 \\
\hline Fractures & 759 & $1.4 \%$ & 735 & $1.3 \%$ & 0.044 & 0.004 \\
\hline Heart failure-hospitalized & 9726 & $17.7 \%$ & 9604 & $17.4 \%$ & 0.222 & 0.006 \\
\hline Heart failure - outpatient & 11,035 & $20.0 \%$ & 11,374 & $20.7 \%$ & -0.616 & -0.015 \\
\hline Hospitalized bleeding & 5594 & $10.2 \%$ & 5637 & $10.2 \%$ & -0.078 & -0.003 \\
\hline Hyperlipidemia & 35,822 & $65.1 \%$ & 35,657 & $64.8 \%$ & 0.300 & 0.006 \\
\hline Hypertension & 45,243 & $82.2 \%$ & 45,509 & $82.7 \%$ & -0.483 & -0.013 \\
\hline Obesity & 12,344 & $22.4 \%$ & 13,209 & $24.0 \%$ & -1.572 & -0.037 \\
\hline Other ischemic heart disease & 22,685 & $41.2 \%$ & 22,769 & $41.4 \%$ & -0.153 & -0.003 \\
\hline Peptic ulcer disease & 234 & $0.4 \%$ & 258 & $0.5 \%$ & -0.044 & -0.007 \\
\hline Renal disease-acute & 5795 & $10.5 \%$ & 6042 & $11.0 \%$ & -0.449 & -0.014 \\
\hline Renal disease - chronic & 9602 & $17.4 \%$ & 10,130 & $18.4 \%$ & -0.959 & -0.025 \\
\hline Smoking & 10,148 & $18.4 \%$ & 10,947 & $19.9 \%$ & -1.452 & -0.037 \\
\hline Stroke, non-inpatient-prior $1-30$ days & 1901 & $3.5 \%$ & 1815 & $3.3 \%$ & 0.156 & 0.009 \\
\hline Stroke, non-inpatient - prior 31-183 days & 2028 & $3.7 \%$ & 2058 & $3.7 \%$ & -0.055 & -0.003 \\
\hline Syncope & 4165 & $7.6 \%$ & 4139 & $7.5 \%$ & 0.047 & 0.002 \\
\hline Transient ischemic attack & 2270 & $4.1 \%$ & 2089 & $3.8 \%$ & 0.329 & 0.017 \\
\hline Walker use & 1296 & $2.4 \%$ & 1256 & $2.3 \%$ & 0.073 & 0.005 \\
\hline \multicolumn{7}{|l|}{ History of use: } \\
\hline $\begin{array}{l}\text { Angiotensin-converting enzyme inhibitors and } \\
\text { angiotensin receptor blockers }\end{array}$ & 31,920 & $58.0 \%$ & 31,913 & $58.0 \%$ & 0.013 & 0.000 \\
\hline Amiodarone & 6688 & $12.2 \%$ & 6726 & $12.2 \%$ & -0.069 & -0.002 \\
\hline Anti-anginal vasodilators & 5600 & $10.2 \%$ & 5595 & $10.2 \%$ & 0.009 & 0.000 \\
\hline Anticoagulants & 6319 & $11.5 \%$ & 6252 & $11.4 \%$ & 0.122 & 0.004 \\
\hline Antiplatelet agents (non-aspirin) & 6908 & $12.6 \%$ & 6974 & $12.7 \%$ & -0.120 & -0.004 \\
\hline Aspirin & 954 & $1.7 \%$ & 1070 & $1.9 \%$ & -0.211 & -0.016 \\
\hline Beta blockers & 39,686 & $72.1 \%$ & 39,851 & $72.4 \%$ & -0.300 & -0.007 \\
\hline Cyclooxygenase (COX-2) inhibitors & 787 & $1.4 \%$ & 750 & $1.4 \%$ & 0.067 & 0.006 \\
\hline
\end{tabular}


Table 1. (continued)

\begin{tabular}{|c|c|c|c|c|c|c|}
\hline \multirow[t]{2}{*}{ Characteristic* } & \multicolumn{2}{|c|}{ Apixaban } & \multicolumn{2}{|c|}{ Warfarin } & \multirow{2}{*}{$\begin{array}{l}\text { Absolute } \\
\text { difference }\end{array}$} & \multirow{2}{*}{$\begin{array}{l}\text { Stanardized mean } \\
\text { difference }\end{array}$} \\
\hline & $\begin{array}{l}\text { N/ } \\
\text { mean }\end{array}$ & $\begin{array}{l}\text { \%/Std } \\
\text { Dev }^{\dagger}\end{array}$ & $\begin{array}{l}N / \\
\text { mean }\end{array}$ & $\begin{array}{l}\% / \text { Std } \\
\text { Dev }^{\dagger}\end{array}$ & & \\
\hline Calcium channel blockers & 21,971 & $39.9 \%$ & 21,772 & $39.6 \%$ & 0.362 & 0.007 \\
\hline Digoxin & 5209 & $9.5 \%$ & 4922 & $8.9 \%$ & 0.521 & 0.018 \\
\hline Disopyramide & 35 & $0.1 \%$ & 30 & $0.1 \%$ & 0.009 & 0.004 \\
\hline Dronedarone & 1113 & $2.0 \%$ & 1003 & $1.8 \%$ & 0.200 & 0.015 \\
\hline Estrogen replacement & 636 & $1.2 \%$ & 623 & $1.1 \%$ & 0.024 & 0.002 \\
\hline Flecainide & 1933 & $3.5 \%$ & 1889 & $3.4 \%$ & 0.080 & 0.004 \\
\hline $\mathrm{H} 2$ antagonists & 2611 & $4.7 \%$ & 2666 & $4.8 \%$ & -0.100 & -0.005 \\
\hline Insulin & 4855 & $8.8 \%$ & 4809 & $8.7 \%$ & 0.084 & 0.003 \\
\hline Loop diuretics & 15,866 & $28.8 \%$ & 16,147 & $29.3 \%$ & -0.511 & -0.011 \\
\hline Metformin & 9344 & $17.0 \%$ & 9436 & $17.1 \%$ & -0.167 & -0.004 \\
\hline Non-statin lipid-lowering agents & 4353 & $7.9 \%$ & 4216 & $7.7 \%$ & 0.249 & 0.009 \\
\hline Other anti-diabetic drugs & 3280 & $6.0 \%$ & 3342 & $6.1 \%$ & -0.113 & -0.005 \\
\hline Potassium-sparing diuretics & 5266 & $9.6 \%$ & 5429 & $9.9 \%$ & -0.296 & -0.010 \\
\hline Prescription non-steroidal anti-inflammatory drugs & 6901 & $12.5 \%$ & 6671 & $12.1 \%$ & 0.418 & 0.013 \\
\hline (NSAIDs) & & & & & & \\
\hline Propafenone & 1095 & $2.0 \%$ & 1009 & $1.8 \%$ & 0.156 & 0.011 \\
\hline Proton pump inhibitors & 13,981 & $25.4 \%$ & 14,037 & $25.5 \%$ & -0.102 & -0.002 \\
\hline Statins & 31,098 & $56.5 \%$ & 31,360 & $57.0 \%$ & -0.476 & -0.010 \\
\hline Sulfonylureas & 5398 & $9.8 \%$ & 5299 & $9.6 \%$ & 0.180 & 0.006 \\
\hline Thiazide diuretics & 13,916 & $25.3 \%$ & 13,753 & $25.0 \%$ & 0.296 & 0.007 \\
\hline \multicolumn{7}{|l|}{ Health service utilization intensity: } \\
\hline Mean number of ambulatory encounters & 11.8 & 9.6 & 11.8 & 9.4 & -0.052 & -0.005 \\
\hline Mean number of emergency room encounters & 0.5 & 0.9 & 0.5 & 1.1 & -0.008 & -0.007 \\
\hline Mean number of inpatient hospital encounters & 0.5 & 0.7 & 0.5 & 0.8 & 0.020 & 0.027 \\
\hline Mean number of generics & 9.5 & 4.9 & 9.5 & 4.9 & 0.053 & 0.011 \\
\hline
\end{tabular}

* Covariates in italics were not included in the propensity score logistic regression model

${ }^{\dagger}$ Value represents standard deviation where no \% follows the value

versus warfarin using the baseline characteristics and potential confounders, including CHA2DS2-VASc ${ }^{22}$ and HAS$\mathrm{BLED}^{23}$ scores, existing risk factors for bleeding, measures of overall health status, and medication use (Table 1) within data partners. New apixaban and warfarin initiators were 1:1 PS-matched using a nearest neighbor matching algorithm with a maximum caliper of 0.05 within each DP and within ICD-9CM or ICD-10 CM era. The PS distributions and covariate balance between apixaban and warfarin cohorts were examined before and after PS matching using standardized mean differences (SMD), with absolute values $>0.10$ indicating imbalance.

For the main analysis, Cox proportional hazard regression was used to estimate the hazard ratios (HR) and 95\% confidence intervals $(95 \% \mathrm{CI})$ for each outcome in the matched cohort of apixaban users compared with the warfarin users. A subgroup analysis by age group (21-64, 65-74, and 75+ years) was conducted.

\section{RESULTS}

A total of 99,442 apixaban and 94,189 warfarin initiators were identified for potential study inclusion from seven data partners who had full propensity score model convergence. Before matching, there were minor differences between cohorts for combined comorbidity score, CHA2DS2VaSc score, HAS-BLED score, cardiac ablation, cardioversion, diabetes, heart failure, hospitalized bleeding, obesity, other ischemic heart disease, renal disease, smoking, anti-anginal vasodilator, digoxin, dronedarone, flecainide, loop diuretic, and prescription non-steroidal anti-inflammatory drug (NSAID) use; for example, the prior combined comorbidity score was 2.7 in apixaban users and 3.2 in warfarin users, SMD - 0.198. There were also slight differences in the number of ambulatory encounters (11.2 apixaban vs. 12.5 warfarin, SMD - 0.132) (Appendix: Table 1). After matching, $55.3 \%$ and $58.4 \%$ of the apixaban and warfarin cohorts respectively were included ( $n=55,038$ in each cohort). Both matched exposure groups were closely balanced for all covariates (Table 1 and Appendix: Fig. 2) and there were 14,172, 17,804, and 20,977 apixaban and warfarin users rematched within subgroups aged $21-64,65-74$, and $\geq 75$ years respectively.

The incidence rate for GI bleeding in the matched apixaban group was 14.85 per 1000 person-years compared with 25 per 1000 person-years in the matched warfarin group (Appendix: Fig. 2). Overall, the HR for GI bleeding in apixaban users compared with warfarin users was 0.57 (95\% CIs 0.50-0.66) (Table 2 and Fig. 1).

A reduced risk of GI bleeding in apixaban compared with warfarin users was seen in all age groups: 21-64 years (HR $0.34,95 \%$ CI $0.21-0.54$ ), 65-74 years (HR $0.51,95 \%$ CI $0.40-0.65$ ), and $\geq 75$ years (HR $0.68,95 \%$ CI $0.56-0.82$ ) (Table 3 and Fig. 1).

The incidence rate for $\mathrm{ICH}$ in the matched apixaban group was 3.46 per 1000 person-years compared with 6.73 per 1000 
Table 2 Adjusted HRs (95\% CIs) for GI Bleeding, ICH, and Ischemic Stroke in Apixaban Compared with Warfarin Users, in Sentinel, from December 28, 2012, to June 30, 2018

\begin{tabular}{|c|c|c|c|c|c|c|}
\hline & Number of new users & Person years at risk & Number of events & $\begin{array}{l}\text { Incidence rate per } \\
1000 \text { person-years }\end{array}$ & $\begin{array}{l}\text { Hazard ratio } \\
(95 \% \text { CI })\end{array}$ & Wald $P$ value \\
\hline \multicolumn{7}{|l|}{ GI bleeding } \\
\hline Apixaban & 55,038 & $20,470.14$ & 304 & 14.85 & \multirow[t]{2}{*}{$0.57(0.50-0.66)$} & \multirow[t]{2}{*}{$<0.001$} \\
\hline Warfarin & 55,038 & $25,243.38$ & 631 & 25.00 & & \\
\hline \multicolumn{7}{|l|}{$\mathrm{ICH}$} \\
\hline Apixaban & 55,038 & $20,517.02$ & 71 & 3.46 & \multirow[t]{2}{*}{$0.53(0.40-0.70)$} & \multirow[t]{2}{*}{$<0.001$} \\
\hline Warfarin & 55,038 & $25,411.13$ & 171 & 6.73 & & \\
\hline \multicolumn{7}{|c|}{ Ischemic stroke } \\
\hline Apixaban & 55,038 & $20,493.77$ & 108 & 5.27 & \multirow[t]{2}{*}{$0.56(0.45-0.71)$} & \multirow[t]{2}{*}{$<0.001$} \\
\hline Warfarin & 55,038 & $25,381.00$ & 226 & 8.90 & & \\
\hline
\end{tabular}

person-years in the matched warfarin group (Appendix: Fig. 3. Overall, the HR for ICH in apixaban users compared with warfarin users was 0.53 (95\% CI 0.40-0.70) (Table 2). The HR was non-significantly reduced in users aged 21-64 years (HR $0.38,95 \%$ CI $0.14-1.05$ ) and in those aged $65-74$ years (HR $0.63,95 \%$ CI $0.39-1.03$ ) and was significantly reduced in those aged $\geq 75$ years (HR $0.52,95 \%$ CI $0.36-0.76$ ) (Table 4 and Fig. 1). Of note, there were only five events among apixaban users aged 21-64 years.

The incidence rate for ischemic stroke in the matched apixaban group was 5.27 per 1000 person-years compared with 8.90 per 1000 person-years in the matched warfarin group (Appendix: Fig. 4). Overall, the HR for ischemic stroke in apixaban users compared with warfarin users was 0.56 (95\% CI 0.45-0.71) (Table 2). The HR was significantly reduced in users aged 21-64 years (HR $0.29,95 \%$ CI $0.13-$ 0.68 ) and users aged $\geq 75$ years (HR $0.57,95 \%$ CI $0.42-0.77$ ) and non-significantly reduced in those aged $65-74$ years (HR 0.70, 95\% CI 0.46-1.07) (Table 5 and Fig. 1).

Results for GI bleeding, ICH, and ischemic stroke overall and across age groups remained consistent in sensitivity analyses when the episode gap was extended to 14 days (data not shown).

\section{DISCUSSION}

Overall, among patients with NVAF, in seven Sentinel data partners, between 2012 and 2018, apixaban use was associated with a statistically significant decreased risk of GI bleeding, $\mathrm{ICH}$, and ischemic stroke compared with warfarin use. When analyses were stratified by age, the risk of GI bleeding and stroke were significantly reduced in apixaban users aged less than 65 years of age. The risk of ICH was also reduced in younger apixaban users, but not significantly so. There were only $20 \mathrm{ICH}$ events in this age group (5 in apixaban users), giving us reduced statistical power to show a significant reduction in risk. GI bleeding was the most commonly observed outcome irrespective of age group and the incidence rate of all outcomes increased with age in both apixaban and warfarin cohorts.

The results were consistent with the findings of a recent FDA study in Medicare among older anticoagulant users (aged $\geq 65$ years) which compared apixaban users to warfarin users from 2010 to 2015 and reported a reduced risk of thromboembolic stroke (HR 0.71, 0.60-0.83), ICH (HR $0.54,0.43-0.68$ ), and major GI bleeding (HR 0.52, 0.450.60). ${ }^{10}$ Two previous studies ${ }^{24,25}$ were identified that

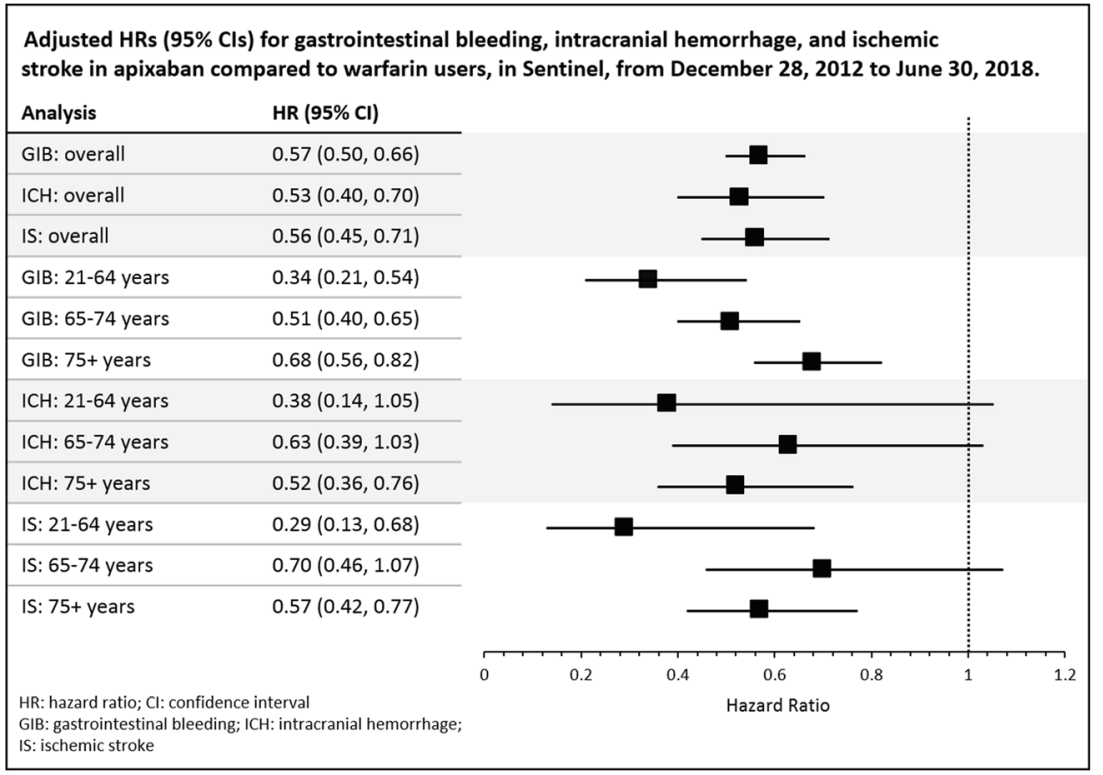

Figure 1 Forest plot showing estimates for each outcome overall and by age group. 
Table 3 Adjusted HRs (95\% CIs) for GI Bleeding, in Apixaban Compared with Warfarin Users, in Sentinel, from December 28, 2012, to June 30, 2018, by Age Group

\begin{tabular}{|c|c|c|c|c|c|c|}
\hline Medical product & $\begin{array}{l}\text { Number of } \\
\text { new users }\end{array}$ & $\begin{array}{l}\text { Person years } \\
\text { at risk }\end{array}$ & $\begin{array}{l}\text { Number of } \\
\text { events }\end{array}$ & $\begin{array}{l}\text { Incidence rate per } \\
1000 \text { person-years }\end{array}$ & $\begin{array}{l}\text { Hazard ratio } \\
(95 \% \text { CI })\end{array}$ & $\begin{array}{l}\text { Wald } \\
P \text { value }\end{array}$ \\
\hline \multicolumn{7}{|c|}{ Age group: $21-64$ years } \\
\hline Apixaban & 14,172 & 4863.16 & 23 & 4.73 & \multirow[t]{2}{*}{$0.34(0.21-0.54)$} & \multirow[t]{2}{*}{$<0.001$} \\
\hline Warfarin & 14,172 & 5197.32 & 77 & 14.82 & & \\
\hline \multicolumn{7}{|c|}{ Age group: $65-74$ years } \\
\hline Apixaban & 17,804 & 7041.44 & 93 & 13.21 & \multirow[t]{2}{*}{$0.51(0.40-0.65)$} & \multirow[t]{2}{*}{$<0.001$} \\
\hline Warfarin & 17,804 & 9032.03 & 220 & 24.36 & & \\
\hline \multicolumn{7}{|c|}{ Age group: $75+$ years } \\
\hline Apixaban & 20,977 & 7778.84 & 175 & 22.50 & \multirow{2}{*}{$0.68(0.56-0.82)$} & \multirow{2}{*}{$<0.001$} \\
\hline Warfarin & 20,977 & $10,139.88$ & 310 & 30.57 & & \\
\hline
\end{tabular}

included some patients with AF below the age of 65 years. However, in the study by Gupta et al., ${ }^{25}$ the proportion of apixaban users aged $18-54$ was only $2.3 \%$ (just 172 patients) and the proportion aged 18-65 was 9.6\% (558 patients) compared with $26.3 \%$ aged $21-64$ in our analysis, with over 14,400 patients in this age group. Yao et al. ${ }^{25}$ included slightly more younger users with $22.7 \%$ of apixaban users (1747 patients) aged between 18 and 64 years. The findings of both studies were consistent with our study and showed that among those with AF, apixaban was associated with lower risks of both stroke and major bleeding compared with warfarin. However, in both studies, the risk estimates provided for stroke and bleeding events were for the entire study population. Neither study provided risk estimates for the stratum of patients below age 65 years. This highlights the need for a large study such as ours to provide evidence of safety and effectiveness of apixaban in younger users.

Our analysis was restricted to a subset of Sentinel data partners as we wanted to examine the association in a different data source from Medicare that also included younger anticoagulant users. However, given that anticoagulants tend to be used more in older age, the proportion of those aged less than 65 years in matched analyses was low (26-28\%). These findings are also consistent with those from the pre-approval ARISTOTLE randomized controlled trial comparing apixaban with warfarin which reported a reduced risk of stroke (HR 0.79, 95\% CI 0.65-0.95), ICH
$(0.42,95 \%$ CI $0.30-0.58)$, and GI bleeding $(0.89,95 \%$ CI $0.70-1.15$ ) among older users (median age 70 years). ${ }^{8}$

This study identified almost 100,000 apixaban users in the Sentinel System reflecting the increasing use of apixaban across time, in all age groups, in the USA since its approval. ${ }^{9}$ Increasing use of apixaban has also been seen in European countries such as Denmark, ${ }^{26}$ Norway, ${ }^{27}$ and Sweden ${ }^{28}$ and this is likely due to its favorable benefit risk compared with warfarin that was also observed in this study.

Our study had a number of strengths including the ability to capture large numbers of anticoagulant users of different ages, the use of propensity score estimation and matching within ICD-specific eras, the use of a new user design to minimize bias, and the ability to span both ICD eras. There were also noteworthy limitations including inability to include all data partners in the analyses due to model convergence issues in the smaller data partners, although the largest were included and as with all observational studies not all confounding factors may have been accounted for in the analysis. Year of cohort entry was not included in the propensity score model and so the effect of secular trends within each ICD era might not have been accounted for. The study was conducted in a US population and therefore the findings may not be generalizable to non-US populations. We included only patients using the 5$\mathrm{mg}$ apixaban strength, assuming a dose of $10 \mathrm{mg}$ daily, which is the standard dose for $\mathrm{AF}$ and in doing so may have excluded some patients with AF using the 2.5-mg apixaban strength. However, further work in the Sentinel System suggested that

Table 4 Adjusted HRs (95\% CIs) for ICH, in Apixaban Compared with Warfarin Users, in Sentinel, from December 28, 2012, to June 30, 2018, by Age Group

\begin{tabular}{|c|c|c|c|c|c|c|}
\hline Medical product & $\begin{array}{l}\text { Number of } \\
\text { new users }\end{array}$ & $\begin{array}{l}\text { Person years } \\
\text { at risk }\end{array}$ & $\begin{array}{l}\text { Number of } \\
\text { events }\end{array}$ & $\begin{array}{l}\text { Incidence rate per } \\
1000 \text { person-years }\end{array}$ & $\begin{array}{l}\text { Hazard ratio } \\
(95 \% \text { CI })\end{array}$ & $\begin{array}{l}\text { Wald } \\
P \text { value }\end{array}$ \\
\hline \multicolumn{7}{|c|}{ Age group: $21-64$ years } \\
\hline Apixaban & 14,172 & 4865.61 & 5 & 1.03 & \multirow[t]{2}{*}{$0.38(0.14-1.05)$} & \multirow[t]{2}{*}{0.063} \\
\hline Warfarin & 14,172 & 5212.11 & 15 & 2.88 & & \\
\hline \multicolumn{7}{|c|}{ Age group: $65-74$ years } \\
\hline Apixaban & 17,804 & 7060.23 & 24 & 3.40 & \multirow[t]{2}{*}{$0.63(0.39-1.03)$} & \multirow[t]{2}{*}{0.067} \\
\hline Warfarin & 17,804 & 9092.44 & 50 & 5.50 & & \\
\hline \multicolumn{7}{|c|}{ Age group: $75+$ years } \\
\hline Apixaban & 20,977 & 7803.61 & 40 & 5.13 & \multirow[t]{2}{*}{$0.52(0.36-0.76)$} & \multirow[t]{2}{*}{$<0.001$} \\
\hline Warfarin & 20,977 & $10,226.84$ & 98 & 9.58 & & \\
\hline
\end{tabular}


Table 5 Adjusted HRs (95\% CIs) for Ischemic Stroke, in Apixaban Compared with Warfarin Users, in Sentinel, from December 28, 2012, to June 30, 2018, by Age Group

\begin{tabular}{|c|c|c|c|c|c|c|}
\hline Medical product & $\begin{array}{l}\text { Number of } \\
\text { new users }\end{array}$ & $\begin{array}{l}\text { Person years } \\
\text { at risk }\end{array}$ & $\begin{array}{l}\text { Number of } \\
\text { events }\end{array}$ & $\begin{array}{l}\text { Incidence rate per } \\
1000 \text { person-years }\end{array}$ & $\begin{array}{l}\text { Hazard ratio } \\
\text { (95\% CI) }\end{array}$ & $\begin{array}{l}\text { Wald } \\
P \text { value }\end{array}$ \\
\hline \multicolumn{7}{|c|}{ Age group: $21-64$ years } \\
\hline Apixaban & 14,172 & 4861.33 & 7 & 1.44 & \multirow[t]{2}{*}{$0.29(0.13-0.68)$} & \multirow[t]{2}{*}{0.004} \\
\hline Warfarin & 14,172 & 5206.03 & 25 & 4.80 & & \\
\hline \multicolumn{7}{|c|}{ Age group: $65-74$ years } \\
\hline Apixaban & 17,804 & 7049.96 & 35 & 4.96 & \multirow[t]{2}{*}{$0.70(0.46-1.07)$} & \multirow[t]{2}{*}{0.098} \\
\hline Warfarin & 17,804 & 9091.32 & 61 & 6.71 & & \\
\hline \multicolumn{7}{|c|}{ Age group: $75+$ years } \\
\hline Apixaban & 20,977 & 7796.20 & 63 & 8.08 & \multirow[t]{2}{*}{$0.57(0.42-0.77)$} & \multirow[t]{2}{*}{$<0.001$} \\
\hline Warfarin & 20,977 & $10,204.43$ & 131 & 12.84 & & \\
\hline
\end{tabular}

the proportion of apixaban $2.5 \mathrm{mg}$ users who had AF was low (21\%) compared with $5 \mathrm{mg}$ users who had AF (80\%).

\section{CONCLUSION}

In NVAF patients of all ages initiating either apixaban or warfarin for stroke prevention in the Sentinel System, apixaban was associated with a decreased risk of GI bleeding, $\mathrm{ICH}$, and ischemic stroke compared with warfarin. Among patients less than 65 years of age, apixaban was associated with a decreased risk of GI bleeding and ischemic stroke.

Acknowledgments: Many thanks are due to those who participated in this project: data partners who provided data/medical records used in the analysis: Aetna, a CVS Health company, Blue Bell, PA; Blue Cross Blue Shield of Massachusetts, Boston, MA; Harvard Pilgrim Health Care Institute, Boston, MA; HealthCore, Inc., Translational Research for Affordability and Quality, Alexandria, VA; HealthPartners Institute, Minneapolis, MN; Humana, Inc., Healthcare Research, Miramar, FL; Kaiser Permanente Colorado Institute for Health Research, Denver, CO; Kaiser Permanente Center for Health Research Hawai'i, Honolulu, HI; Kaiser Permanente Mid-Atlantic States, Mid-Atlantic Permanente Research Institute, Rockville, MD; Kaiser Permanente Northern California, Division of Research, Oakland, CA; Kaiser Permanente Northwest Center for Health Research, Portland, OR; Kaiser Permanente Washington Health Research Institute, Seattle, WA; Marshfield Clinic Research Institute, Marsh field, WI; Meyers Primary Care Institute, Worcester, MA; OptumInsight Life Sciences Inc., Boston, MA; and Vanderbilt University Medical Center, Department of Health Policy, Nashville, TN, through the TennCare Division of the Tennessee Department of Finance \& Administration which provided data. The authors thank Rong Tilney, MS; Rajani Rajbhandari, MS; and Anita Wagner, PhD, at the Sentinel Operations Center for their programming and clinical review assistance.

Corresponding Author: Marie Bradley, PhD, MPharm, MSc.PH; Office of Surveillance and Epidemiology, Center for Drug Evaluation and Research, Food and Drug Administration, Silver Spring, MD, USA (e-mail: marie.bradley@fda.hhs.gov).

Funding This project was supported by Task Order HHSF22301012T under Master Agreement HHSF223201400030I from the US Food and Drug Administration (FDA). The FDA approved the study protocol including statistical analysis plan and reviewed and approved this manuscript. Coauthors from the FDA participated in the result interpretation and in the preparation and decision to submit the manuscript for publication. The FDA had no role in data collection, management, or analysis. The authors from the Sentinel Operations Center at Harvard Pilgrim Health Care Institute received funding support from the FDA as part of Sentinel Initiative (through the
Department of Health and Human Services contract number HHSF223200910006I).

\section{Compliance with Ethical Standards:}

This study was classified as public health surveillance by the Food and Drug Administration (FDA) and was exempt from review by its Research in Human Subjects Committee. It was not appropriate to involve patients or the public in the design, conduct, reporting, or dissemination plans of this work.

Disclaimer: The opinions expressed are the author's own and do not reflect the view of the Food and Drug Administration, the Department of Health and Human Services, or the United States government.

Conflict of Interest: The authors declare that they do not have a conflict of interest.

\section{REFERENCES}

1. Hylek EM, Go AS, Chang $\mathbf{Y}$, et al. Effect of intensity of oral anticoagulation on stroke severity and mortality in atrial fibrillation. N Engl J Med 2003;349(11):1019-26. doi: https://doi.org/10.1056/ NEJMoa022913 [published Online First: 2003/09/12]

2. Lip GY, Lane DA. Stroke prevention in atrial fibrillation: a systematic review. JAMA 2015;313(19):1950-62. doi: https://doi.org/10.1001/ jama.2015.4369 [published Online First: 2015/05/20]

3. Feinberg WM, Blackshear JL, Laupacis A, et al. Prevalence, age distribution, and gender of patients with atrial fibrillation. Analysis and implications. Arch Intern Med 1995;155(5):469-73. [published Online First: 1995/03/13]

4. Prevention CfDCa. Atrial fibrillation fact sheet. Atlanta: Centers for Disease Control and Prevention, 2017.

5. Moss JD, Cifu AS, Guidelines AATFoP. Management of anticoagulation in patients with atrial fibrillation. JAMA 2015;314(3):291-2. doi: https://doi.org/10.1001/jama.2015.3088 [published Online First: 2015/07/22]

6. Connolly SJ, Ezekowitz MD, Yusuf S, et al. Dabigatran versus warfarin in patients with atrial fibrillation. N Engl J Med 2009;361(12):1139-51. doi: https://doi.org/10.1056/NEJMoa0905561 [published Online First: 2009/09/01]

7. Giugliano RP, Ruff CT, Braunwald E, et al. Edoxaban versus warfarin in patients with atrial fibrillation. N Engl J Med 2013;369(22):2093-104. doi: https://doi.org/10.1056/NEJMoal310907 [published Online First: 2013/11/21]

8. Granger CB, Alexander JH, McMurray JJ, et al. Apixaban versus warfarin in patients with atrial fibrillation. $N$ Engl J Med 2011;365(11):981-92. doi: https://doi.org/10.1056/NEJMoa1107039 [published Online First: 2011/08/30]

9. Zhu J, Alexander GC, Nazarian S, et al. Trends and variation in oral anticoagulant choice in patients with atrial fibrillation, 2010-2017. Pharmacotherapy 2018;38(9):907-20. doi: https://doi.org/10.1002/ phar.2158 [published Online First: 2018/06/20] 
10. Graham DJ, Baro E, Zhang R, et al. Comparative stroke, bleeding, and mortality risks in older medicare patients treated with oral anticoagulants for nonvalvular atrial fibrillation. Am J Med 2019;132(5):596-604 e11. doi: https://doi.org/10.1016/j.amjmed.2018.12.023 [published Online First: 2019/01/15]

11. Platt R, Carnahan RM, Brown JS, et al. The U.S. Food and Drug Administration's Mini-Sentinel program: status and direction. Pharmacoepidemiol Drug Saf 2012;21 Suppl 1:1-8. doi: https://doi. org/10.1002/pds.2343 [published Online First: 2012/01/25]

12. Curtis LH, Weiner MG, Boudreau DM, et al. Design considerations, architecture, and use of the Mini-Sentinel distributed data system. Pharmacoepidemiol Drug Saf 2012;21 Suppl 1:23-31. doi: https://doi. org/10.1002/pds.2336 [published Online First: 2012/01/25]

13. Platt R, Brown JS, Robb M, et al. The FDA Sentinel Initiative - an evolving national resource. N Engl J Med 2018;379(22):2091-93. doi: https://doi.org/10.1056/NEJMp1809643 [published Online First: 2018/11/30]

14. Cunningham A, Stein CM, Chung CP, et al. An automated database case definition for serious bleeding related to oral anticoagulant use. Pharmacoepidemiol Drug Saf 2011;20(6):560-6. doi: https://doi.org/10. 1002/pds.2109 [published Online First: 2011/03/10]

15. Kokotailo RA, Hill MD. Coding of stroke and stroke risk factors using international classification of diseases, revisions 9 and 10. Stroke 2005;36(8):1776-81. doi: https://doi.org/10.1161/01.STR.0000174293. 17959.al [published Online First: 2005/07/16]

16. Roumie CL, Mitchel E, Gideon PS, et al. Validation of ICD-9 codes with a high positive predictive value for incident strokes resulting in hospitalization using Medicaid health data. Pharmacoepidemiol Drug Saf 2008;17(1):20-6. doi: https://doi.org/10.1002/pds.1518 [published Online First: 2007/11/06]

17. Tirschwell DL, Longstreth WT, Jr. Validating administrative data in stroke research. Stroke 2002;33(10):2465-70. [published Online First: 2002/10/05]

18. Wahl PM, Rodgers K, Schneeweiss S, et al. Validation of claims-based diagnostic and procedure codes for cardiovascular and gastrointestinal serious adverse events in a commercially-insured population. Pharmacoepidemiol Drug Saf 2010;19(6):596-603. doi: https://doi.org/ 10.1002/pds. 1924 [published Online First: 2010/02/09]

19. Panozzo CA, Welch EC, Woodworth TS, et al. Assessing the impact of the new ICD-10-CM coding system on pharmacoepidemiologic studies-an application to the known association between angiotensin-converting enzyme inhibitors and angioedema. Pharmacoepidemiol Drug Saf 2018;27(8):829-38. doi: https://doi.org/10.1002/pds.4550 [published Online First: 2018/06/28]
20. Panozzo CA, Woodworth TS, Welch EC, et al. Early impact of the ICD10-CM transition on selected health outcomes in 13 electronic health care databases in the United States. Pharmacoepidemiol Drug Saf 2018;27(8):839-47. doi: https://doi.org/10.1002/pds.4563 [published Online First: 2018/06/28]

21. Services CfMM. 2017 ICD-10-CM and GEMs. 2017

22. Lip GY, Nieuwlaat $\mathbf{R}$, Pisters $\mathbf{R}$, et al. Refining clinical risk stratification for predicting stroke and thromboembolism in atrial fibrillation using a novel risk factor-based approach: the euro heart survey on atrial fibrillation. Chest 2010;137(2):263-72. doi: https://doi.org/10.1378/ chest.09-1584 [published Online First: 2009/09/19]

23. Pisters R, Lane DA, Nieuwlaat R, et al. A novel user-friendly score (HASBLED) to assess 1-year risk of major bleeding in patients with atrial fibrillation: the Euro Heart Survey. Chest 2010;138(5):1093-100. doi: https://doi.org/10.1378/chest.10-0134 [published Online First: 2010/03/20]

24. Gupta K, Trocio J, Keshishian A, et al. Effectiveness and safety of direct oral anticoagulants compared to warfarin in treatment naive non-valvular atrial fibrillation patients in the US Department of defense population. BMC Cardiovasc Disord 2019;19(1):142. doi: https://doi.org/10.1186/ s12872-019-1116-1 [published Online First: 2019/06/15]

25. Yao X, Abraham NS, Sangaralingham LR, et al. Effectiveness and safety of dabigatran, rivaroxaban, and apixaban versus warfarin in nonvalvular atrial fibrillation. J Am Heart Assoc 2016;5(6). doi: https://doi.org/10. 1161/JAHA. 116.003725 [published Online First: 2016/07/15]

26. Staerk L, Fosbol EL, Gadsboll K, et al. Non-vitamin K antagonist oral anticoagulation usage according to age among patients with atrial fibrillation: temporal trends 2011-2015 in Denmark. Sci Rep 2016;6:31477. doi: https://doi.org/10.1038/srep31477 [published Online First: 2016/08/12]

27. Kjerpeseth LJ, Ellekjaer H, Selmer R, et al. Trends in use of warfarin and direct oral anticoagulants in atrial fibrillation in Norway, 2010 to 2015. Eur J Clin Pharmacol 2017;73(11):1417-25. doi: https://doi.org/ 10.1007/s00228-017-2296-1 [published Online First: 2017/07/25]

28. Komen J, Forslund T, Hjemdahl P, et al. Effects of policy interventions on the introduction of novel oral anticoagulants in Stockholm: an interrupted time series analysis. Br J Clin Pharmacol 2017;83(3):64252. doi: https://doi.org/10.1111/bcp.13150 [published Online First: 2016/10/13]

Publisher's Note Springer Nature remains neutral with regard to jurisdictional claims in published maps and institutional affiliations. 